\title{
Temáticas como estratégias discursivas de legitimação social em programas televisiwos brasileiros
}

Themes as discursive strategies for social legitimation

in Brazilian television programs

Anna Christina Bentes ${ }^{1}$

Universidade Estadual de Campinas (UNICAMP), Campinas, SP, Brasil.

Resumo: Nosso trabalho tem como principal objetivo mostrar, a partir de análises previamente realizadas, o papel das configurações temáticas de dois programas televisivos brasileiros, de forma a compreender os efeitos de legitimação social que esse recurso discursivo produz quando colocado em uso. Ao observarmos as temáticas mais gerais de dois programas, concluímos que estas constituem-se em estratégias discursivas que auxiliam na promoção e legitimação das posições de determinados atores sociais no campo midiático brasileiro.

Palavras-Chave: Legitimação social. Gêneros televisivos brasileiros. Tópico discursivo. Tema. Ator social.

Abstract: The main objective of our work is to show the role of the thematic configurations of two Brazilian television programs in order to understand the effects of social legitimation that this discursive resource produces when put into use. When we look at the more general themes of two programs, we conclude that these are discursive strategies that help to promote and to legitimize the positions of certain social actors in Brazilian media field.

Key-words: Social legitimation. Brazilian televisive genres. Discursive topic. Theme. Social Actor.

\section{Introdução}

O contexto de escrita deste artigo é o ano de 2017. O início desse ano foi marcado por dois fatos sociopolíticos importantes, muito relacionados ao nosso tema e, em especial, aos resultados das pesquisas desenvolvidas por Bentes (2013a; 2013b) que serão apresentadas e discutidas ao longo do texto.

1 Professora do Departamento de Linguística do Instituto de Estudos da Linguagem da Universidade Estadual de Campinas (UNICAMP). e-mail: annafapesp@hotmail.com 
Um primeiro fato: o prefeito eleito em 2016, para um mandato de quatro anos, da maior cidade da América Latina, a cidade de São Paulo, nos primeiros dias de janeiro de 2017, promove a campanha "Cidade Linda". Uma das primeiras ações da campanha performatizada pelo próprio prefeito eleito foi a de "limpar" a cidade dos grafites, começando por apagar, com tinta cinza, os grafites do maior mural de arte urbana a céu aberto da América Latina.

Um segundo fato: as chacinas ocorridas em penitenciárias de di-

Anna

Christina

Bentes ferentes estados brasileiros, Amazonas, Roraima, Rio Grande do Norte e São Paulo durante os primeiros dias de 2017. A respeito da primeira chacina, ocorrida no presídio de Manaus, no dia 05 de janeiro de 2017, o Secretário Nacional da Juventude do governo federal afirma nas redes sociais: "Tinha era que matar mais, tinha que fazer uma chacina por semana". Ele pediu exoneração poucas horas depois da declaração.

Como esses fatos podem estar relacionados à discussão empreendida neste texto? A relação que pode ser estabelecida entre o contexto acima descrito e a discussão aqui empreendida é a de que tanto a ação do prefeito de São Paulo como a fala de uma ex-autoridade nacional em juventude são ações de (des)legitimação ${ }^{2}$ de um conjunto de práticas socioculturais e discursivas relacionadas a políticas públicas de direitos humanos que foram ganhando legitimidade, especialmente, mas não só, no interior do campo midiático ao longo dos últimos 15 anos.

Considerando o cenário descrito acima, este artigo buscará apresentar alguns resultados de pesquisas desenvolvidas sobre um corpus de gêneros ${ }^{3}$ midiáticos que tratam majoritariamente de questões sociais e que são voltados para a divulgação de iniciativas diversas das periferias de grandes cidades e/ou para as periferias de grandes cidades e

2 Nossa abordagem para questão da (des)legitimação também considera as postulações de Falcone (2008), para quem a (des)legitimação de atores e grupos sociais pode ser compreendida como "uma atividade resultante de complexas relações sociais, norteada por modelos cognitivos, sendo o discurso uma importante força propulsora para tal processo". (p. 78)

3 Ao longo desse artigo, assumimos a perspectiva de Hanks (2008) sobre o conceito de gênero do discurso, especialmente considerando as questões apontadas por Bentes e Rezende (2014) como sendo fundamentais na reflexão do autor sobre o referido conceito: (i) as relações de poder instauradas nos e pelos próprios gêneros e as funções estabilizadoras/oficializadoras que exercem em muitas esferas; (ii) o fato de que os gêneros ao serem produzidos, reconhecidos e usados também permitem a explicitação de uma série de procedimentos de natureza "meta", tais como a sua própria nomeação e as várias formas de "arranjar/organizar/mobilizar" as vozes sociais que o compõem; (iii) a questão da contextualização radical de um determinado gênero, o que envolve não apenas os aspectos relativos a sua centração indicial, mas, fundamentalmente, as formas de acabamento que irão fornecer pistas sobre os seus graus de completude/incompletude. 
para minorias sociais em geral: os programas televisivos Manos e Minas (exibido pela TV Cultura, canal aberto da televisão brasileira) e Conexões Urbanas (exibido pelo Multishow, canal fechado da televisão brasileira).

De acordo com Bourdieu (2004), os processos de legitimação de uma determinada variedade linguística e a manutenção dessa legitimidade pressupõem um trabalho permanente de correção, do qual se incubem tanto os locutores singulares como as instituições especialmente organizadas para essa finalidade. A nosso ver, o foco sobre os processos de legitimação social envolve necessariamente a compreensão do papel não apenas dos recursos linguísticos, mas, especialmente, das estratégias de produção textual-discursiva na manutenção da legitimidade conquistada pelos atores sociais (BOURDIEU, 1983) no interior de determinado campo social.

William Hanks, em seu texto "Bourdieu e as práticas de linguagem"

Temáticas como estratégias discursivas de legitimação social em programas televisivos brasileiros (2008), argumenta que a legitimidade é conferida à determinadas práticas de linguagem na medida em que são escolhidas/referendadas por outros grupos, pelas classes dominantes e pelo grande público. Acreditamos que se, por um lado, a legitimação social em relação a determinados atores ou práticas sociais por parte de determinados grupos sociais, especialmente por parte da classe dominante, caracteriza-se pelo reconhecimento e atribuição de distinção a esses atores ou práticas, por outro lado, é preciso que essas práticas legitimadas a partir de um trabalho social conjunto sejam continuamente reiteradas e colocadas em jogo.

Sendo assim, é possível afirmar que se há reconhecimento de/ e atribuição de um valor social distinto a determinados atores e práticas sociais é porque há também um trabalho contínuo por parte dos atores sociais para manter a posição legítima que passaram a ocupar no interior de um determinado campo. Esse trabalho estratégico é constitutivo dos processos de legitimação social em geral e, especificamente, daqueles que envolvem os atores e as práticas sociais nos programas televisivos em análise. $\mathrm{O}$ foco desse artigo recai justamente sobre um aspecto desse trabalho estratégico dos atores sociais envolvidos na produção e exibição dos programas Manos e Minas e Conexões Urbanas, a serem apresentados em seguida.

O trabalho situa-se nos interesses das abordagens que se voltam para as relações entre texto e sociedade, compreendendo que os textos são modos de atuação na vida social, dado que estão repletos de demandas para que compreendamos e aceitemos (ou não) conhecimentos e expectativas socialmente concebidos sobre seus referentes e temáticas e produzamos, também socialmente, sentido(s) sobre (e a partir de) eles. 
Além disso, é importante ressaltar que a discussão das análises desenvolvidas enfocam textos produzidos no interior da indústria cultural que, segundo Bourdieu (2004), obedece a lei da concorrência para a conquista do maior mercado possível. o campo da indústria cultural é, segundo o autor, especificamente organizado com vistas à produção de bens culturais destinado à não produtores de bens culturais ("o grande público"), que podem ser recrutados tanto nas frações não intelectuais das classes dominantes ("o público cultivado"), como nas demais classes.

Anna

Christina

Bentes

104

Em função do exposto, nosso trabalho tem como principal objetivo mostrar, a partir de análises previamente realizadas, o papel das configurações temáticas dos programas televisivos acima mencionados de forma a compreender os efeitos de legitimação que esse recurso discursivo produz quando colocado em uso.

Ao observarmos as temáticas mais gerais de ambos os programas e ao considerarmos que a noção de temática diz respeito não apenas aos conteúdos desenvolvidos, mas também aos pontos de vista que organizam esses conteúdos, podemos dizer que, com base em uma visão bakhtiniana (Bakhtin, 1986; 1992), retomada por Hanks (2008), os programas televisivos constituem-se em diferentes quadros de orientação para a produção de discursos ${ }^{4}$, quadros estes que estão organizados por determinados recursos de linguagem que promovem e legitimam as posições de certos atores sociais no campo midiático brasileiro.

\section{Os programas televisivos Manos e Minas e Conexões Urbanas}

Os programas televisivos Manos e Minas ${ }^{5}$ discutidos nesse trabalho referem-se ao período entre julho de 2008 e outubro de 2009. Nesse período, o programa pode ser descrito como um programa de auditório e de va-

4 Em consonância com uma perspectiva de base sociocognitiva, assumiremos ao longo desse projeto a concepção de discurso proposta por Íñiguez (2003; 1997) e Íñiguez e Antaki (2004), resumida na formulação de Garay, Íñiguez e Martinez (2005, p. 110-11): “um conjunto de práticas linguísticas que mantém e promovem certas relações sociais". 0 interesse desse grupo de pesquisadores é o de investigar como os próprios atores sociais elaboram suas interações sociais e verbais a partir de perspectivas variáveis e diversas do mundo social, considerando que a "orientação do discurso para funções específicas é uma indicação de seu caráter construtivo" (p. 111). o grupo também dialoga com autores que consideram centralmente três premissas: a do interesse sobre como as pessoas constroem a realidade social; a da consideração da linguagem não como uma descrição da realidade, mas como uma construção dessa realidade; e a da compreensão da linguagem como uma prática social (p. 112).

5 Entre agosto de 2010 e abril de 2011, o programa Manos e Minas foi interrompido, retornando em junho de 2011, com algumas modificações, mas ainda era um programa de auditório. De maio de 2014 a dezembro de 2015, o programa se transformou em um programa de variedades, focado mais em atividades artísticas musicais, estruturado por meio de reportagens e entrevistas. A partir de junho de 2016, o programa voltou a ser um programa de auditório e assim continua. 
riedades, produzido e veiculado pela TV Cultura do Estado de São Paulo, estruturado por meio de (i) interações do apresentador com o auditório e com convidados no palco e (ii) de reportagens externas e (iii) de quadros específicos do programa. Ele foi apresentado, ao longo desses dois anos,

pelos rappers Rappin Hood e Thaíde, em 2008 e 2009 respectivamente.

Segundo Granato (2011), o programa Manos e Minas se diferenciou, naquela época, dos demais programas de auditório por estar ancorado nos elementos do hip-hop e por ter objetivos diferentes dos programas de auditório da TV brasileira: o de constituir-se em um programa produzido pela periferia e para a periferia sobre o cotidiano social e cultural desse espaço social.

O programa Conexões Urbanas é um programa de reportagens, dado que trata os assuntos de forma mais aprofundada e privilegia dife-

Temáticas como estratégias discursivas de legitimação social em programas televisivos brasileiros rentes perspectivas e atores sociais. Com a apresentação de José Junior, coordenador-executivo do Grupo Cultural AfroReggae, definido como uma organização que luta pela transformação social através da cultura e da arte, o programa estreou no canal Multishow em 13 de outubro de 2008, e sua sétima e última temporada foi finalizada em março de 2015. Os programas analisados no trabalho de Bentes, Mariano e Accetturi (2015) compreendem todo o período de exibição do programa.

Nosso interesse pelos programas Conexões Urbanas e Manos e Minas está relacionado ao trabalho de pesquisa com objetos sociais (gêneros do discurso, ações de textualização e práticas de linguagem) vinculados ao chamado campo da cultura popular urbana. Os programas Manos e Minas e Conexões Urbanas compõem o corpus do atual projeto de pesquisa (BP/ CNPq - 309845/2013) intitulado "Estabilização e inovação dos gêneros midiáticos: tópico discursivo e categorização social" (Bentes, 2013b) e também compuseram um corpus maior de gêneros que fizeram parte do projeto de pesquisa "É nóis na fita: sobre a formação de registros e a elaboração de estilos no campo da cultura popular urbana paulista" (Proc. Fapesp $n^{\circ} .2009 / 08369-8$ ), que vigorou de março de 2010 a fevereiro de 2013.

\section{Resultados de análises desenvolvidas sobre as temáticas dos programas Manos e Minas e Conexões Urbanas}

No âmbito dos projetos de pesquisa acima mencionados, alguns dos resultados mais gerais das pesquisas sobre a questão da configuração temática dos programas podem ser vistos nos trabalhos de Granato (2011) e Bentes, Mariano e Acceturi (2015; 2016). A base 
teórica assumida é a noção de tópico discursivo desenvolvida pelo Grupo Organização Textual-Interativa do Projeto de Gramática do Português Falado (PGPF) (JUBRAN et al., 2002), revisitada por Jubran (2006a, 2006b).

O trabalho de Granato (2011) mostra, por meio da análise dos tópicos discursivos, os traços temáticos que caracterizam o programa Manos e Minas no período de 2008 a 2009. A análise dos tópicos discursivos desse programa de auditório revela que as grandes te-

Anna Christina

Bentes máticas não se relacionam especifica e/ou exclusivamente ao entretenimento mas sim (i) às práticas sociais, culturais, educacionais de periferia; (ii) às dificuldades cotidianas dos sujeitos da periferia; (iii) aos preconceitos sociais e raciais vivenciados pelos sujeitos da periferia; (iv) ao universo do hip-hop, com vistas à valorização e à legitimação dessa prática cultural e (v) à crítica à condição de exclusão social de muitos sujeitos de periferia, à falta de emprego e de educação de qualidade, à falta de investimentos governamentais na periferia. (Granato, 2011, p. 227)

Bentes, Mariano e Accetturi (2015) fizeram um levantamento da configuração temática do programa Conexões Urbanas, considerando o período de sete anos (outubro de 2008 a março de 2015). o programa enfocou, de forma contínua e regularmente distribuída em suas sete temporadas, sete temáticas: "Projetos/Organizações Não-Governamentais (ONGs)", "Instituições de Segurança Pública", "Outras Instituições”, "Indivíduos", "Questões Sociais", “Grupos sociais" e "Lugares de tensão social". O levantamento dessas temáticas ocorreu a partir da consideração dos vídeos e dos resumos dos 111 episódios do programa, exibidos entre os anos de 2008 e 2015, procurando uma característica importante do tema, a saber, os processos de centração dos tópicos discursivos que são trabalhados no contexto do programa.

É importante ressaltar que o Conexões Urbanas conferiu em suas temporadas uma grande visibilidade às ações de organizações da própria sociedade civil (ONGs) que atuam em campos sociais específicos, como o da saúde e o da educação de populações econômica e socialmente desprivilegiadas do campo e da cidade, tais como as populações ribeirinhas, carcerárias, das periferias e das favelas brasileiras e de alguns outros países. Foram mostrados os trabalhos de ONGs cujas atuações incidem diretamente sobre minorias sociais tais como jovens negros, mulheres negras, ex-detentos e prostitutas. 
Além de tematizar especificamente algumas instituições de segurança pública (principalmente a Polícia Militar e instituições prisionais), o programa busca fazê-lo a partir da ótica de cada um dos atores sociais que delas participam, "policiais" e "bandidos", "presidiários", "ex-detentos”, sendo que todas essas categorizações foram produzidas no interior dos programas. Bentes, Mariano e Accetturi (2015) afirmam que essa temática é construída em diferentes episódios (16 episódios de 111, totalizando 14\% do total de programas). No caso dos episódios sobre presídios, as autoras afirmam que, ao longo dos programas, os presidiários mostram as suas rotinas e os difíceis processos de reinserção na sociedade. Ouve-se também os especialistas que, em geral, falam sobre condições de vida dos presos em diversas penitenciárias do Brasil e sobre as possibilidades

Temáticas como estratégias discursivas de legitimação social em programas televisivos brasileiros de reinserção dos ex-detentos na sociedade. A temática "Questões sociais" pode ser observada nos episódios que abordam diversos tipos de violência (urbana, no trânsito, homofobia, pedofilia, contra trabalhadores rurais), legalização das drogas, racismo, anistia a ex-detentos, a participação de menores no mundo do crime, as vantagens da pirataria, para mencionar os mais importantes e menos “espetaculares", mas bastante polêmicos. Apresentamos, a seguir, um gráfico que ilustra a quantidade e os tipos de temáticas dos 111 episódios ao longo dos sete anos do programa.

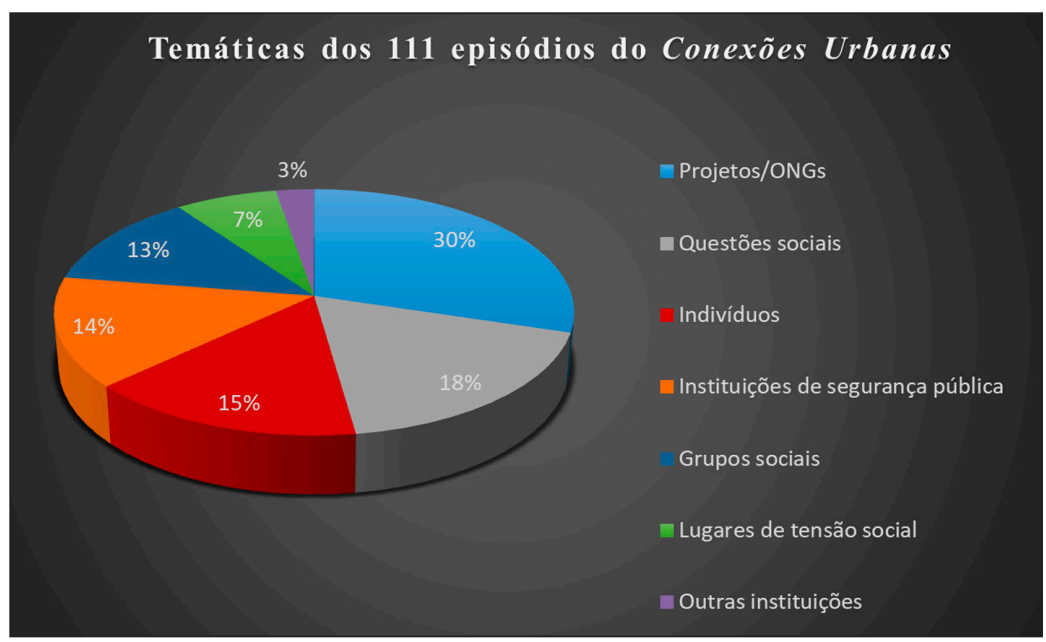

Gráfico 1. Quantificação das temáticas de todos os episódios do programa Conexões Urbanas ao longo de sete temporadas (Fonte: Bentes, Mariano, Accetturi, 2015) 
A partir de um outro levantamento feito com base no corpus de 111 programas do Conexões Urbanas, também é possível dizer que a seleção das temáticas produz um impacto imediato sobre outra seleção: a dos atores sociais a serem entrevistados. Uma primeira tipologia dos atores sociais postulada por Bentes, Mariano e Accetturi (2016) mostra que predominam no programa os seguintes atores: a) trabalhadores autônomos, subordinados ou profissionais liberais; b) pessoas em situação de vulnerabilidade; c) protagonistas sociais; d) porta-vozes; e) profissionais

Anna

Christina

Bentes

108 da mídia; f) servidores públicos; g) especialistas; h) outros. Alguns atores sociais estão presentes sempre, como fonte de legitimação das temáticas propostas, tais como os especialistas e outros profissionais de mídia.

As temáticas mais engajadas socialmente que estruturam os dois programas pressupõem a necessária aparição de atores sociais específicos, tais como detentos, traficantes, menores infratores, usuários de drogas, desempregados, etc. (pessoas em situação de vulnerabilidade), ou ainda, ativistas, líderes de movimentos, coordenadores de projetos, empreendedores sociais etc. (protagonistas sociais).

\section{Sobre os efeitos de legitimação produzidos pela emergên- cia das temáticas nos programas televisivos analisados}

Bentes, Mariano e Accetturi (2015) afirmam que a predominância da temática "Projetos/ONGs" no programa Conexões Urbanas conferiu-lhe a identidade objetivada por seus idealizadores, a saber, a de um programa jornalístico televisivo que dá visibilidade (i) a ações sociais promovidas por ONGs ou outras organizações que minimizem a desigualdade social e (ii) a ações empreendedoras. Essa estratégia evidencia o afastamento do Conexões Urbanas de outras produções televisivas jornalísticas, caracterizadas por uma seleção de conteúdos pautada principalmente pela busca de temas de natureza "sensacional" e/ou "espetacular" (BOURDIEU, 1997).

Em relação ao programa Manos e Minas, é possível afirmar, segundo Granato (2011, p. 237), que a orientação do programa, considerando-o como um gênero do discurso, vai na direção da oficialização e da regularização (Hanks, 2008) das práticas culturais da periferia: o programa contou e conta com atores sociais legitimados pelas comunidades de periferia para tratar de temáticas relativas a ela; a estruturação temática e multisemiótica do programa adere a/ e reflete os valores sociais das comunidades e serve para a divulgação de suas práticas culturais com vistas à valorização dessas na/pela televisão. 
Sendo assim, com base nas formulações da autora, é possível afirmar que a configuração temática do programa Manos e Minas deriva da inter-relação entre (i) os sistemas de valores sociais compartilhados por grupos sociais específicos e diferenciados entre si, (ii) a seleção de um conjunto de tópicos discursivos, (iii) a presença de legítimos representantes do mundo social apresentado e (iv) a manipulação de recursos semióticos e linguísticos concernentes com a(s) identidades sociais representadas.

As configurações temáticas dos programas Manos e Minas e Conexões Urbanas mostram que a chamada "grande mídia" é um lócus importante para a observação das lutas por (des)legitimação de determinados atores, práticas e valores sociais. Sabemos que os programas trabalham as temáticas e cada tópico discursivo a elas relacionadas de

Temáticas como estratégias discursivas de legitimação social em programas televisivos brasileiros modo não homogêneo. Mesmo assim, é possível dizer que os valores sociais legitimados, na grande maioria das vezes, são a solidariedade, a justiça social, a cooperação, a tolerância e a paz ${ }^{6}$.

Em relação aos atores sociais, sua presença sistemática nos programas e o trabalho multisemiótico e discursivo a que são submetidos suas identidades sociais e pontos de vista promove o que Bourdieu (2011, p. 161) denomina "o trabalho de naturalização que todo grupo tende a produzir em vista de se legitimar, de justificar plenamente sua existência".

Além disso, acreditamos que os processos de legitimação dos atores, práticas e valores sociais relativos a comunidades periféricas e a setores sociais desassistidos e vulneráveis só foi possível em função de uma "aliança ambígua" e "mais ou menos duradoura", descrita por Bourdieu (2011) da seguinte forma:

\begin{abstract}
os produtores culturais, dominados entre os dominantes, oferecem aos dominados, mediante uma espécie de desvio do capital cultural acumulado, os meios de constituírem objetivamente a sua visão do mundo e a representação de seus interesses numa teoria explícita e em instrumentos de representação institucionalizados - organizações sindicais, partidos, tecnologias sociais de mobilização e de manifestação, etc. (p. 157-158)
\end{abstract}

6 A esse respeito, ver o trabalho de Bentes, Mariano e Accetturi (2016) sobre as estratégias de argumentação no programa Conexões Urbanas, e também a dissertação de mestrado de Granato (2011). 
Voltando ao início desse artigo, acreditamos que a aliança a qual se refere Bourdieu ao mesmo tempo em que aconteceu e conseguiu se manter, também foi sendo questionada e combatida ao longo do tempo em que se abriram os pequenos espaços de legitimação social para os setores mais marginalizados e desassistidos da sociedade brasileira, representados mesmo que apenas parcialmente pelos dois programas analisados.

Atualmente, a cultura hip hop, a cultura de periferia e os atores sociais nelas envolvidos estão sendo fortemente combatidos pelas

Anna ações de alto impacto simbólico e social do recém-eleito prefeito de São Christina Paulo, ao apagar grafites representantes da chamada arte urbana. As vozes mais críticas do sistema penal brasileiro estão, atualmente, lutando para continuar enfrentando criticamente a ideologia punitivista, espetacularmente reforçada em nosso meio social pela instauração da chamada Operação Lava-Jato, em março de 2014, ano das últimas eleições presidenciais e legislativas diretas no Brasil.

A temática "Anistia", tratada em 2009, no Conexões Urbanas, estruturada com base na tese da necessidade de uma lei de anistia a criminosos como uma alternativa à privação de liberdade no Brasil, parece impensável como pauta de um programa televisivo de reportagens do campo da mídia tradicional (aberta ou fechada) nos dias do hoje no Brasil. A tese do "perdão judicial" divulgada nesse programa foi deslegitimada a ponto de, no contexto atual, grande parte dos setores médios da sociedade brasileira, representados pelas vozes de várias autoridades nacionais, defenderem e concordarem com a afirmação de que "bandido bom é bandido morto".?

No entanto, as lutas por (des)legitimação vão continuar, tendo como um recurso fundamental as práticas textuais-discursivas e as estratégias de organização que lhe são inerentes. Nossa esperança é a de que as tomadas de posição dos diversos atores sociais menos favorecidos social e economicamente nos diferentes campos possam ser continuamente mantidas e/ou transformadas, como diz o mestre, "de modo mais ou menos difícil, pela história" (Bourdieu, 2011, p. 161), e que os atores desenvolvam cada vez mais uma consciência sobre o importante papel das estratégias de organização textual-discursiva no contínuo trabalho de manutenção das legitimidades conquistadas.

7 A respeito da consolidação entre os brasileiros da ideologia do "bandido bom é bandido morto", há uma grande circulação de textos na internet, sendo os seguintes bons exemplos do exame, por parte de estudiosos do campo do direito, desse processo pelo qual passa a sociedade brasileira há algum tempo: http://jornalggn.com.br/noticia/expansao-do-poder-punitivo-e-a-ideologia-da-"nao-ideologia-por-lucas-battisti 


\section{REFERÊNCIAS}

BAKHTIN, Mikhail. Marxismo e filosofia da linguagem. São Paulo: Hucitec, 1986

Temáticas como estratégias Estética da criação verbal. São Paulo: Martins Fontes, 1992.

BENTES, Anna Christina. "É nóis na fita": a formação de registros e a elaboração de estilos no campo da cultura popular paulista. Relatório final do Projeto de Pesquisa financiado pela FAPESP. Proc. No. 2009/083639-8, 2013a. discursivas de legitimação social em programas televisivos brasileiros

Estabilização e inovação dos gêneros midiáticos: tópico discursivo e categorização social. Projeto de Pesquisa de Bolsa produtividade. CNPq. 2013b.

BENTES, Anna Christina; REZENDE, Renato Cabral. o texto como objeto de análise. In: Gonçalves, A. V.; Góis, M. L. de S. (Orgs.) O fazer científico. v. 2. Campinas: Mercado de Letras, 2014, p.137-176.

BENTES, Anna Christina; MARIANO, Rafaela Defendi; ACCETTURI, Ana Cecília. Temas e estratégias de referenciação em Conexão. ReVEL, v. 13, n. 25, p. 316-354, agosto de 2015.

. "Eu quero muito trabalhar um tema: estratégias argumentativas no programa televisivo Conexões Urbanas. 2016. (no prelo)

BOURDIEU, Pierre. A economia das trocas simbólicas. Sérgio Micelli (Orgs.) São Paulo: Perspectiva, 2004.

O poder simbólico. Lisboa: Edições 70, 2011.

. Sobre a televisão. Rio de Janeiro: Jorge Zahar, 1997.

Questões de sociologia. Rio de Janeiro: Marco Zero, 1983. 
FALCONE, Karina. (Des)legitimação: ações discursivo-cognitivas para o processo de categorização social. Tese (Doutorado em Letras). Universidade Federal de Pernambuco, Recife, 2008.

GARAY, Ana; ÍNIIGUEZ, Lupicinio; MARTINEZ, Luz Ma. La perspectiva discursiva en psicologia social. Subjetividad y processos cognitivos, UCES, p. 105-130, 2005.

Anna GRANATO, Lívia Bertolazzi. Gêneros discursivos em foco: dos Christina programas televisivos Manos e Minas e Altas Horas. Dissertação Bentes (Mestrado em Linguística). Universidade Estadual de Campinas, Campinas, 2011.

HANKS, William F. Pierre Bourdieu e as práticas de linguagem. Língua como prática social: das relações entre língua, cultura e sociedade a partir de Bourdieu e Bakhtin. BENTES, A. C.; REZENDE, R. C.; MACHADO, M. A. (Orgs.). São Paulo: Cortez Editora, 2008, p. 33-63.

JUBRAN, Clélia Cândida de Abreu Spinardi et al. Organização tópica da conversação. In: ILARI, R. (Org.). Gramática do português falado. v. II. Campinas: Editora da UNICAMP, 2002, p. 341-377.

. Tópico discursivo. In: JUBRAN, C. C. A. S.; KOCH, I. G. V. (Orgs.). Gramática do Português Culto Falado no Brasil: Construção do texto falado. 1 ed. Campinas: Editora da UNICAMP, 2006a, v. I, p. 89-132.

- Revisitando a noção de tópico discursivo. Caderno de Estudos Linguísticos v. 48, Campinas, p. 33-41, 2006b.

Recebido em 06 de março de 2017. Aceito em 05 de maio de 2017. 